\title{
STUDIES ON AEROSOL OPTICAL PROPERTIES AT HIGH ALTITUDE STATION IN WESTERN HIMALAYAS USING RAMAN LIDAR
}

\author{
Shishir Kumar Singh ${ }^{1,2}$, Jaswant ${ }^{1,2}$, Radhakrishnan S.R. ${ }^{12^{*}}$, Davender Sethi ${ }^{1,2}$ and Chhemendra \\ Sharma ${ }^{1,2}$ \\ ${ }^{1}$ Environmental Sciences and Biomedical Metrology Division \\ ${ }^{2}$ CSIR-National Physical Laboratory, Dr. K. S. Krishnan Marg, New Delhi-110012, India \\ *Email: rkrishnan@nplindia.org
}

\begin{abstract}
The aerosol optical properties have been investigated using the Raman lidar system for the month of November 2018 at the western Himalayan station of Palampur. Before deriving the optical properties, the lidar data has been applied with initial pre-processing such as Dead time correction, atmospheric noise correction, temporal and spatial averaging, range correction, gluing etc. The optical properties such as backscatter coefficient, extinction coefficient and linear depolarization ratio have been derived by using the inversion algorithm proposed by Fernald. The results show that the backscatter coefficient was found in the range from $9.00 \mathrm{E}-9 \mathrm{~m}^{-1} \mathrm{sr}^{-1}$ to 4.97E- $6 \mathrm{~m}^{-1} \mathrm{sr}^{-1}$ and the extinction coefficient was found in the range from $3.16 \mathrm{E}-7 \mathrm{~m}^{-1}$ to $1.74 \mathrm{E}-4 \mathrm{~m}^{-1}$. The Linear depolarization ratio was in the range from 0.0179 to 0.621 with lower values at near heights suggesting the dominance of spherical particles at the lower heights. We have also observed a cloud layer at a height of $9.5 \mathrm{~km}$ to $12.1 \mathrm{~km}$ with high depolarization ratio during the observation period on 22/11/2018.
\end{abstract}

\section{INTRODUCTION}

The effects of atmospheric aerosols on climate have large uncertainties including their direct and indirect effects related to aerosol-cloud interactions. The climatic effects of aerosol depend on its physical, chemical and optical properties along with its vertical distribution. This enables the need of advanced lidar systems which can provide the optical and microphysical properties of aerosols with its vertical distribution [1].

In India, only few measurements of aerosol vertical profiles by lidar have been carried out. Long-term measurements and continuous measurements of aerosol vertical distribution are even less. In this paper, we are presenting the measurement of aerosol vertical profiles in Palampur, Himachal Pradesh, India. The measurements are based on a Raman lidar which provides information on the vertical distribution of optical presence of aerosols and clouds. [2]

\section{METHODOLOGY}

\subsection{Sampling Site}

A Raymetrics Raman Lidar system, LR111-D200 is installed at the National Physical Laboratory's remote monitoring station at the campus of CSIRInstitute of Himalayan Bioresource Technology (IHBT), Palampur, Himachal Pradesh, India at an altitude of $1347 \mathrm{~m}$ above mean sea level to study the vertical profiles of physical and optical properties of aerosols and clouds. Palampur is located in the lower Himalayan region of Western Himalayas and lies within the latitude $32.1109^{\circ} \mathrm{N}$ and longitude $76.5363^{\circ}$ E. Figure 1 shows the topographic map of Palampur. It is the first ground based lidar facility in the Western Himalayan region of India.

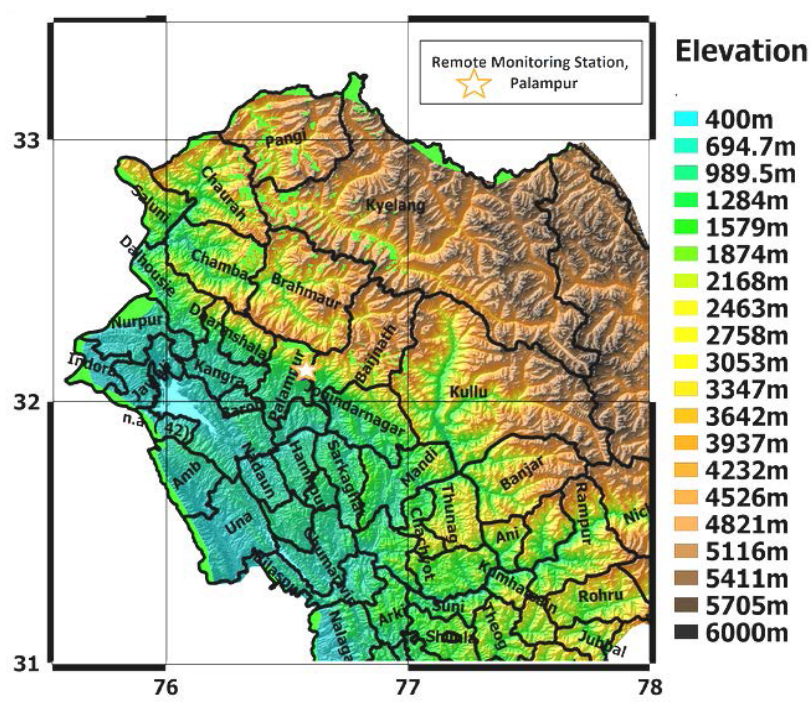

Figure 1: Topographic map of Palampur 


\subsection{The Lidar System}

This lidar system is operated at $355 \mathrm{~nm}$ with Raman channel at $387 \mathrm{~nm}$ having a spatial resolution of $7.5 \mathrm{~m}$. The return signal is analyzed by using the software provided by the manufacturer for further processing. The copolarized and cross polarized Mie channels of the lidar system provides the linear depolarization ratio which is an indicator of the shape of the aerosol/cloud particle. The nitrogen Raman channel at $387 \mathrm{~nm}$ of the lidar system can be used to derive the lidar ratio, which is an important parameter for the identification of different types of aerosols in the troposphere. The technical specifications of the Raman lidar system are given in Table 1.

\begin{tabular}{|c|c|}
\hline \multicolumn{2}{|c|}{ Table 1: Specifications of Raman Lidar } \\
\hline Pulsed Laser Source & $\begin{array}{c}\text { Nd:YAG (Quantel } \\
\text { ULTRA100 Series) }\end{array}$ \\
\hline Wavelength & $355 \mathrm{~nm}$ \\
\hline Energy / Pulse & $32.8 \mathrm{~mJ}$ \\
\hline Repetition Rate & $20 \mathrm{~Hz}$ \\
\hline Pulse Width & $5.60 \mathrm{nsec}$ \\
\hline $\begin{array}{c}\text { Laser Beam } \\
\text { Divergence }\end{array}$ & $<0.8 \mathrm{mrad}$ \\
\hline Telescope Type & Cassegrain \\
\hline Primary Diameter & $200 \mathrm{~mm}$ \\
\hline Secondary Diameter & $48 \mathrm{~mm}$ \\
\hline $\begin{array}{c}\text { Transmitter-Receiver } \\
\text { Distance }\end{array}$ & $212 \mathrm{~mm}$ \\
\hline Field of View & $\begin{array}{c}2.3 \mathrm{mrad} \text { (adjustable from } \\
0.5 \text { to 3mrad) }\end{array}$ \\
\hline Detectors & 3 PMTs \\
\hline $\begin{array}{c}\text { Data Acquisition Mode } \\
\text { Both Analog and Photon } \\
\text { Counting }\end{array}$ \\
\hline
\end{tabular}

\subsection{Lidar Data Analysis}

The Raman lidar data for the $22^{\text {nd }}$ November 2018 has been used for the study. The depolarisation ratio of the lidar system allows us to separate spherical particles from non-spherical. The lidar ratio gives us information about the properties and origin of particles by giving the ratio of the extinction and backscatter coefficient [2]. The Palampur has a very clear environment with very less anthropogenic activities, so a lidar ratio of $35 \mathrm{sr}$ has been taken at $355 \mathrm{~nm}$ [6]. Before deriving optical properties from the raw lidar data, it has been temporally and spatially averaged. Other than this, the raw lidar data has been preprocessed with other corrections such as dead time correction of photon counting (PC) signal, background correction, bin shift correction, range correction, gluing etc. by the software provided by manufacturer. Figures $2 \& 3$ shows the aerosol backscatter coefficient, extinction coefficient and linear depolarization ratio at $355 \mathrm{~nm}$ wavelength for $22^{\text {nd }}$ Nov. 2018.

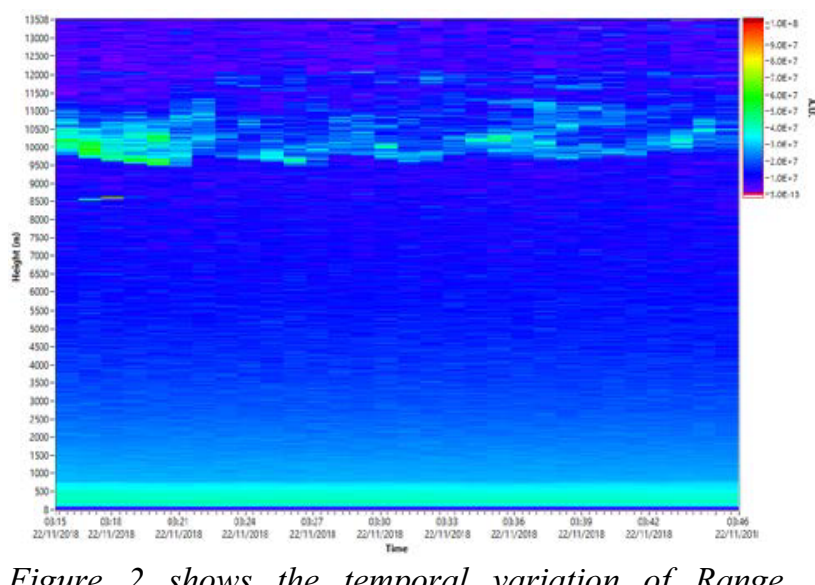

Figure 2 shows the temporal variation of Range Corrected Signal for $22^{\text {nd }}$ November 2018

The figure 2 shows the temporal variation of range corrected signal (RCS) of $22^{\text {nd }}$ November 2018. In this figure, we can see that there is high loading of aerosol over the Lidar station upto $1 \mathrm{~km}$ and at height of $10-12 \mathrm{~km}$ we can observe the clouds.

The backscatter coefficient was found in the range from $3.62 \mathrm{E}-8 \mathrm{~m}^{-1} \mathrm{sr}^{-1}$ to $1.76 \mathrm{E}-6 \mathrm{~m}^{-1} \mathrm{sr}^{-1}$ in low altitude and $9.00 \mathrm{E}-9 \mathrm{~m}^{-1} \mathrm{sr}^{-1}$ to $4.97 \mathrm{E}-6 \mathrm{~m}^{-1} \mathrm{sr}^{-1}$ in high altitude $(9500 \mathrm{~m}-12100 \mathrm{~m})$. The extinction coefficient was found in the range from $1.27 \mathrm{E}-6$ $\mathrm{m}^{-1}$ to $6.15 \mathrm{E}-5 \mathrm{~m}^{-1}$ in low altitude (upto $800 \mathrm{~m}$ ) and $3.16 \mathrm{E}-7 \mathrm{~m}^{-1}$ to $1.74 \mathrm{E}-4 \mathrm{~m}^{-1}$ in high altitude $(9500 \mathrm{~m}-12100 \mathrm{~m})$. The value of the backscatter coefficient and extinction coefficient were high near the ground $(0-1 \mathrm{~km})$ and then it decreased with the altitude. Figure 3 shows that beyond 1000 meters there were very few aerosols and the atmosphere can be considered clear. 
The Linear depolarization ratio was in the range from 0.0179 to 0.621 . The depolarization values were close to zero at the lower heights suggesting the dominance of spherical particles at the lower heights. We have also observed a cloud layer at a height of $9500 \mathrm{~m}-12100 \mathrm{~m}$ with high depolarization ratio.

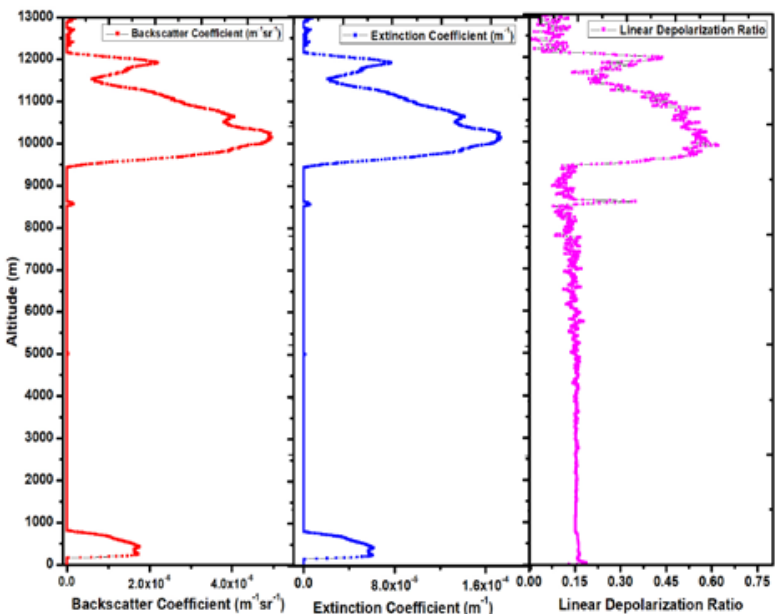

Figure 3 shows the backscatter coefficient, extinction coefficient and linear depolarization ratio of $22^{\text {nd }}$ November 2018.

To trace the sources of air parcel, we have also plotted the HYSPLIT (Hybrid Single-Particle Lagrangian Integrated Trajectory) 3 days Back Trajectory for at three different levels, $500 \mathrm{~m}$ agl (above ground level), $6000 \mathrm{~m} \mathrm{agl}$ and $13000 \mathrm{~m} \mathrm{agl}$ in figure 4.

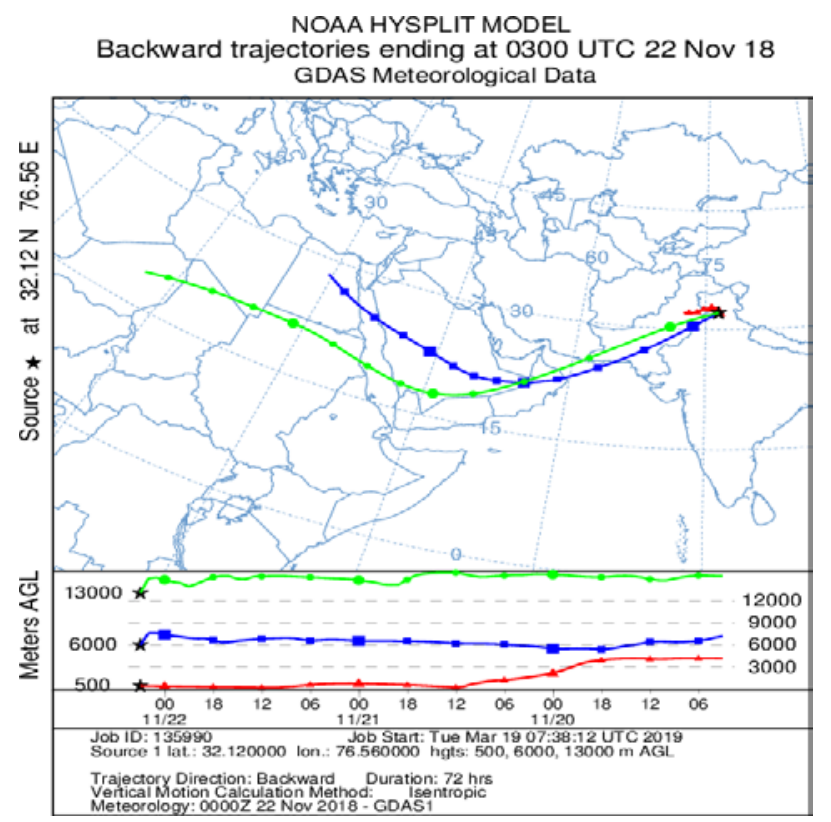

Figure 4 shows three-day backward trajectory by NOAA HYSPLIT
Results show that most of the aerosol loading was due to regional emissions at lower heights of the station. The air parcel arrived at the higher heights of station was from Africa and the western region of the India. This also shows that the cloud loading at higher altitude was originated from the north of Africa having high depolarization ratio.

\section{CONCLUSION}

The aerosol optical properties over a western Himalayan region Palampur have been investigated by a Raman lidar system for the month November 2018. The raw lidar signal has been pre-processed before deriving optical properties from it. The results show that the aerosol loading was high at the lower heights with the dominance of the spherical particles. A cloud layer was also observed at the height of $9.5 \mathrm{~km}$ to $12 \mathrm{~km}$ above the ground level.

\section{ACKNOWLEDGEMENTS}

Authors are grateful to Director, NPL for necessary support. Authors are thankful to CSIR network project PSC-0112 for necessary financial support. Mr. Shishir Kumar Singh is thankful to University Grant Commission (UGC)) for providing research fellowship and also to Academy of Scientific and Innovative Research (AcSIR) for facilitating as its PhD student.

\section{REFERENCES}

[1] M. Komppula et al. Atmos. Chem. Phys., 12, 45134524 (2012).

[2] M. N. Young et al. Atmospheric Research 86, 76 87 (2007)

[3] F. G. Fernald Appl. Opt. 23, 652-653 (1984)

[4] A. Ansmann et al. Optics Letter Vol. 15, Issue 13, 746-748 (1990)

[5] A. Ansmann et al. Applied Physics B 55(1): 18-28 $1(1992)$

[6] K. Sasson et al. Geophysical Research Letters, Vol. 34, L08803 (2007) 